\title{
Effectiveness, Tolerability, and Safety of Ectoine- Containing Mouthwash Versus Those of a Calcium Phosphate Mouthwash for the Treatment of Chemotherapy-Induced Oral Mucositis: A Prospective, Active-Controlled, Non-interventional Study
}

\author{
Van Anh Dao (D) Andreas Bilstein · Sabrina Overhagen · Lajos Géczi • \\ Zoltán Baráth · Ralph Mösges
}

Received: March 13, 2018 / Published online: May 9, 2018

(C) The Author(s) 2018

\section{ABSTRACT}

Introduction: Oral mucositis is a frequent complication of cancer chemotherapy and radiotherapy. Ectoine is a natural extremolyte that can stabilize biological membranes and

Enhanced digital content To view enhanced digital content for this article go to https://doi.org/10.6084/ m9.figshare.6127478.

Electronic supplementary material The online version of this article (https://doi.org/10.1007/s40487018-0060-z) contains supplementary material, which is available to authorized users.

V. A. Dao · R. Mösges

CRI - Clinical Research International Ltd., Genter Str. 7, 50672 Cologne, Germany

A. Bilstein $(\varangle) \cdot S$. Overhagen

Bitop AG, Carlo-Schmid-Allee 5, 44263 Dortmund, Germany

e-mail: bilstein@bitop.de

\section{Géczi}

Department of Oncological Internal Medicine and Clinical Pharmacology "C", National Institute of Oncology Hungary, Budapest 1026, Hungary

\section{Z. Baráth}

National Korányi Institute of TB and Pulmonology, Budapest 1121, Hungary

\section{R. Mösges}

Faculty of Medicine, Institute of Medical Statistics and Computational Biology, University of Cologne, Kerpener Straße 62, 50937 Cologne, Germany counteract inflammatory reactions. This study investigated ectoine-containing mouthwash for the prophylaxis and the treatment of oral mucositis. Its effectiveness, tolerability, and safety were compared to those of the local standard-of-care calcium phosphate mouthwash.

Methods: This prospective, active-controlled, observational study was conducted in two study centers in Hungary from January 2016 to October 2017. Sixty patients undergoing chemotherapy were to be recruited and allocated to one of three treatment arms: prophylactic treatment with ectoine (20 patients), active treatment with ectoine (20 patients), or calcium phosphate (20 patients). The study lasted 21 days, comprising four visits on day 0 , day 7, day 14, and day 21.

Results: In all, 45 patients were included in the study (prophylactic ectoine, 10 patients; active ectoine, 20 patients; calcium phosphate, 15 patients). In the prophylactic ectoine group, few mucositis symptoms of mild or moderate severity occurred throughout the study. In the active ectoine and the calcium phosphate groups, symptoms of mild and moderate severity at inclusion were reduced significantly after 14 days of treatment and were mostly resolved at the end of the study. The difference between the active ectoine and the calcium phosphate groups was not significant. According to patients' assessments, ectoine mouthwash was 
more effective and tolerable than calcium phosphate mouthwash.

Conclusions: Ectoine mouthwash is safe, well tolerated, and effective for the active treatment of oral mucositis following chemotherapy. Its effectiveness is comparable to that of calcium phosphate. Patients prefer ectoine mouthwash to calcium phosphate mouthwash.

Trial Registration Number: NCT02816515. Funding: Bitop AG (Dortmund, Germany). Plain Language Summary: Plain language summary available for this article.

\section{PLAIN LANGUAGE SUMMARY}

Oral mucositis is the inflammation of the mucosa of the oral cavity. It is a frequent complication of cancer chemotherapy and radiotherapy. Approximately $20-40 \%$ of patients undergoing chemotherapy suffer from oral mucositis. It is very painful, impairs eating, drinking, and quality of life. One of the most effective yet simple measures to prevent and treat oral mucositis is oral care with mouthwash. Ectoine is a natural substance that was discovered in halophilic (salt-loving) bacteria. Ectoine can protect these bacteria against dehydration because it can attract water molecules and strengthen biological membranes. Ectoine is used to treat many diseases caused by allergens, UV light, air pollution, heat, and dryness. Ectoine Ectoin $^{\circledR}$ ) mouthwash is produced by bitop AG (Dortmund, Germany) to treat dry mouth and other symptoms of inflamed oral mucosa.

This study investigated ectoine mouthwash for the treatment of oral mucositis following chemotherapy. It was compared to the local standard-of-care calcium phosphate mouthwash. One group of patients was treated with ectoine mouthwash and the other with calcium phosphate mouthwash. After 14 days, mucositis symptoms were substantially reduced in both groups. After 21 days, all patients were almost cured of oral mucositis. Additionally, after the treatment, patients rated how effective and tolerable the treatment was. Here, more patients treated with ectoine rated their treatment as effective and tolerable than those treated with calcium phosphate.

This study shows that ectoine mouthwash is tolerable and effective for the treatment of mucositis. Patients preferred ectoine mouthwash to calcium phosphate mouthwash.

Keywords: Chemotherapy;

Ectoine;

Mouthwash; Mucositis; Oral care

\section{INTRODUCTION}

Oral mucositis, clinically defined as inflammation of the mucosal lining of the oral cavity, is a frequent complication of cancer chemotherapy and radiotherapy. It occurs in $20-40 \%$ of patients undergoing standard chemotherapy [1] and in almost every patient receiving bone marrow transplantation [2]. Risk factors for the development of mucositis include age, nutritional status, type of malignancy, and oral care during cancer treatment [3]. Mucositis is very painful, often requires analgesics, and impairs eating, drinking, and quality of life. Severe mucositis can even necessitate reducing or discontinuing cancer therapy. Medical costs for mucositis are considerable because of symptom management, nutrition support, and hospitalization [4, 5].

There are numerous interventions for mucositis, such as basic oral care, anti-inflammatory agents, anti-radical scavengers, antimicrobials, coating agents, laser therapy, and cryotherapy. Basic oral care, despite being the least invasive treatment option, is vital in preventing infections. The Multinational Association of Supportive Care in Cancer and International Society of Oral Oncology (MASCC/ISOO) Clinical Practice Guidelines for Mucositis recommend basic oral care for preventing oral mucositis following all cancer treatments in all age groups. However, at present, there is no standard treatment guideline for oral mucositis [4]. A systematic review on currently available oral care protocols, dental care as well as mouthwash containing saline, sodium bicarbonate, chlorhexidine, mixed medication, and calcium phosphate has yielded insufficient and conflicting evidence [6]. 
The development of mucositis is divided into five phases, each of which is characterized by inflammatory and apoptosis-triggering factors, such as reactive oxygen species (initiation phase), TNF- $\alpha$, IL-1 $\beta$, IL- 6 , the mitogen-activated protein kinase pathway, the ceramide signaling pathway (damage response and signal amplification phase) as well as bacterial and fungal colonization (ulceration phase) [7-10].

Ectoine is a natural extremolyte which has been shown to counteract inflammatory reactions involving IL-6, IL-8, TNF- $\alpha$, IL-1 $\beta$ [11-13], the ceramide signaling pathway [14], and the mitogen-activated protein kinase signaling pathway [15]. It has also been shown to rescue cells from apoptosis [16, 17]. Furthermore, ectoine can stabilize biological membranes and rehydrate dry, irritated mucosa [18-20], which is essential for the body's defense against oral infections. These membrane-stabilizing and inflammation-reducing effects of ectoine-containing products have been demonstrated in several clinical studies [21-23]. Taken together, ectoine can be expected to thwart the development of oral mucositis.

This study investigated ectoine-containing mouthwash for the prophylaxis and the treatment of oral mucositis. Its effectiveness, tolerability, and safety were compared to those of the local standard-of-care calcium phosphate mouthwash.

\section{MATERIALS AND METHODS}

\section{Study Design}

This prospective, active-controlled, observational study was conducted in two study centers in Hungary from January 2016 to October 2017. Patients were included in the trial after the decision about the treatment option had been made on the basis of the patients' preference. The study complied with laws and regulations effective in Hungary, namely $\$ 17$ para (1), point c) of Government Regulation 235/2009. (X.20.). It was carried out in accordance with legal statutes and regulations for the protection of human subjects. This study was approved by the Department of Medical Devices at the
Healthcare Registration and Training Center (ENKK), Budapest, Hungary (Reference number: 001654/2016). It is listed at clinicaltrials.gov under the number NCT02816515.

We aimed to recruit 60 male and female adult patients who had an inoperable/metastatic small cell lung cancer (SCLC) tumor, nonsmall cell lung cancer (NSCLC) tumor, gastrointestinal stromal tumor, renal cell carcinoma, or pancreatic neuroendocrine tumor. Patients receiving targeted tyrosine kinase inhibitor anticancer therapy were treated with sunitinib (Sutent $^{\circledR}$, Pfizer Pharma GmbH). Patients could be chemotherapy-naïve or have had chemotherapy before the study.

Patients were allocated to one of three treatment arms: prophylactic treatment with ectoine (20 patients), active treatment with ectoine (20 patients), or calcium phosphate (20 patients). In the prophylactic ectoine arm, patients received ectoine mouthwash on the first day of chemotherapy. In the active ectoine arm and the calcium phosphate arm, treatment was initiated when mucositis occurred.

The study lasted 21 days, comprising an initial visit (V1) on day 0, visit 2 (V2) on day 7, visit 3 (V3) on day 14, and visit 4 (V4) on day 21.

\section{Study Medications}

Ectoine $\left(\right.$ Ectoin $\left.^{\circledR}\right)$ mouthwash is a registered medical device manufactured by bitop AG (Dortmund, Germany). An ampoule (single dose unit) contains $5 \mathrm{ml}$ preservative-free solution of ectoine (2\%), hydroxyethyl cellulose (for better viscosity), and xylitol (for sweetness) in phosphate buffer and water. It was administered at least three times daily, each time for $30 \mathrm{~s}$ with 1-2 ampoules.

Caphosol $^{\circledR}$ mouthwash (EUSA Pharma, UK) is a supersaturated calcium phosphate solution. It was used at least four times daily according to the manufacturer's instructions.

\section{Clinical Assessments}

Effectiveness was assessed on the basis of symptom scores and mucositis grading results 
(World Health Organization (WHO) classification) [24]. The symptoms of dry mucosa, coated tongue, mucosal irritation, unpleasant breath, decreased saliva production, pain, swelling, ulcer, difficulties speaking, and difficulties eating/drinking were assessed by the physicians together with the patients at each visit on a 4 -point scale $(0=$ none, $1=$ mild, $2=$ moderate, and 3 = severe). The grade of mucositis was determined for each patient at each visit: grade $0=$ none, grade $\mathrm{I}=$ mild (oral soreness, erythema), grade $\mathrm{II}=$ moderate (oral erythema, ulcers, solid diet tolerated), grade III = severe (oral ulcers, liquid diet only), and grade IV = life-threatening (oral alimentation impossible). Changes in symptom scores and mucositis grades from V1 to V2, V3, and V4 were compared between groups.

At the last visit, patients rated the overall effectiveness and tolerability of the treatment as well as its effectiveness against the individual symptoms of redness, burning sensation, swelling, pain, mucosa irritation, and dry mucosa $(0=$ very poor, $1=$ poor, $2=$ neither poor nor good, 3 =good, and $4=$ very good). Additionally, patients were asked to rate their likelihood of buying or recommending the product after the study $(0=$ no, $1=$ maybe, and $2=$ yes $)$.

All adverse events and serious adverse events were to be documented. Their possible relations to the treatment were evaluated by the investigators.

\section{Statistical Analyses}

Statistical analyses were performed using SAS version 9.3 (SAS Institute Inc., Cary, NC, USA). As this was an exploratory study, no sample size calculation was performed. There was a 95\% probability that side effects occurring at an incidence of $5.9 \%$ or higher would have been detected (Clopper-Pearson).

Symptom scores, general effectiveness, and tolerability that had been measured on a standard scale were analyzed descriptively, and the Wilcoxon signed-rank test was used to detect significant differences between the baseline scores and the final scores during and after treatment. Frequencies and percentages of mucositis grades were presented by visit and treatment group. Frequencies and percentages were determined for the variables from the patient questionnaires at the end of the study. Comparisons between treatment groups were performed using the two-sided Fisher's exact test with an $\alpha$-level of $5 \%$.

\section{Compliance with Ethics Guidelines}

All procedures performed in studies involving human participants were in accordance with the ethical standards of the institutional and/or national research committee and with the 1964 Declaration of Helsinki and its later amendments or comparable ethical standards. Informed consent was obtained from all individual participants included in the study

\section{RESULTS}

\section{Study Population}

In all, 45 patients were recruited: 10 patients were allocated to the prophylactic ectoine arm, 20 to the active ectoine arm, and 15 to the calcium phosphate arm. The distribution of female and male patients in these groups was 1 and 9, 7 and 13, and 6 and 9, respectively. The mean age of patients was similar across all groups (prophylactic ectoine, $61.10 \pm$ 7.11 years; active ectoine, $61.55 \pm 7.52$ years, and calcium phosphate, $63.87 \pm 6.45$ years). In total, 29 patients had lung cancer (SCLC/ NSCLC) and 16 patients had metastatic renal cell carcinoma (mRCC). These 16 patients were treated with sunitinib.

\section{Prophylactic Treatment with Ectoine}

During prophylactic treatment with ectoine, 3 out of $10(30 \%)$ patients were completely free of symptoms (WHO grade 0). Symptoms of mild intensity (WHO grade I) were reported in 2 patients at V2 and V3. In 6 patients (60\%), mild symptoms (WHO grade I) occurred at V4 (Tables 1, 2, Fig. 1). 
Table 1 Changes in mucositis grades (WHO classification) over time

\begin{tabular}{|c|c|c|c|c|c|}
\hline & Grade 0 & Grade I & Grade II & Grade III & Grade IV \\
\hline \multicolumn{6}{|c|}{ Prophylactic ectoine } \\
\hline \multicolumn{6}{|l|}{ V1 } \\
\hline$N$ & 10 & - & - & - & - \\
\hline$\%$ & 100.0 & & & & \\
\hline \multicolumn{6}{|l|}{$\mathrm{V} 2$} \\
\hline$N$ & 9 & 1 & - & - & - \\
\hline$\%$ & 90.0 & 10.0 & & & \\
\hline \multicolumn{6}{|l|}{$\mathrm{V} 3$} \\
\hline$N$ & 8 & 1 & 1 & - & - \\
\hline$\%$ & 80.0 & 10.0 & 10.0 & & \\
\hline \multicolumn{6}{|l|}{ V4 } \\
\hline$N$ & 3 & 6 & 1 & - & - \\
\hline$\%$ & 30.0 & 60.0 & 10.0 & & \\
\hline \multicolumn{6}{|c|}{ Active ectoine } \\
\hline \multicolumn{6}{|l|}{ V1 } \\
\hline$N$ & - & 8 & 9 & 3 & - \\
\hline$\%$ & & 40.0 & 45.0 & 15.0 & \\
\hline \multicolumn{6}{|l|}{$\mathrm{V} 2$} \\
\hline$N$ & 1 & 6 & 11 & 2 & - \\
\hline$\%$ & 5.0 & 30.0 & 55.0 & 10.0 & \\
\hline \multicolumn{6}{|l|}{ V3 } \\
\hline$N$ & 2 & 15 & 2 & 1 & - \\
\hline$\%$ & 10.0 & 75.0 & 10.0 & 5.0 & \\
\hline \multicolumn{6}{|l|}{ V4 } \\
\hline$N$ & 16 & 2 & 1 & 1 & - \\
\hline$\%$ & 80.0 & 10.0 & 5.0 & 5.0 & \\
\hline \multicolumn{6}{|c|}{ Calcium phosphate } \\
\hline \multicolumn{6}{|l|}{$\mathrm{V} 1$} \\
\hline$N$ & - & 3 & 11 & - & 1 \\
\hline$\%$ & & 20.0 & 73.3 & & 6.7 \\
\hline \multicolumn{6}{|l|}{$\mathrm{V} 2$} \\
\hline$N$ & - & 3 & 11 & - & 1 \\
\hline$\%$ & & 20.0 & 73.3 & & 6.7 \\
\hline
\end{tabular}


Table 1 continued

\begin{tabular}{clllll}
\hline & Grade 0 & Grade I & Grade II & Grade III & Grade IV \\
\hline V3 & & & & & - \\
$N$ & - & 9 & 5 & 35.7 & - \\
$\%$ & 64.3 & & - & - \\
V4 & & 7 & 1 & \\
$N$ & 6 & 50.0 & 7.1 & \\
\hline
\end{tabular}

Table 2 Symptom scores

\begin{tabular}{|c|c|c|c|c|c|}
\hline Symptom & Treatment & $\begin{array}{l}\text { V1 } \\
(\text { mean } \pm S D)\end{array}$ & $\begin{array}{l}\mathrm{V} 2 \\
(\text { mean } \pm S D)\end{array}$ & $\begin{array}{l}\mathrm{V3} \\
(\text { mean } \pm S D)\end{array}$ & $\begin{array}{l}\text { V4 } \\
(\text { mean } \pm S D)\end{array}$ \\
\hline \multirow[t]{3}{*}{ Dry mucosa } & $\begin{array}{l}\text { Prophylactic } \\
\text { ectoine }\end{array}$ & $0.0 \pm 0.0$ & $0.2 \pm 0.6$ & $0.5 \pm 0.8$ & $0.5 \pm 0.8$ \\
\hline & Active ectoine & $1.7 \pm 0.6$ & $1.4 \pm 0.6$ & $1.0 \pm 0.7$ & $0.4 \pm 0.9$ \\
\hline & $\begin{array}{l}\text { Calcium } \\
\text { phosphate }\end{array}$ & $1.9 \pm 0.5$ & $1.7 \pm 0.6$ & $1.3 \pm 0.5$ & $0.6 \pm 0.5$ \\
\hline \multirow[t]{3}{*}{ Mucosa irritation } & $\begin{array}{l}\text { Prophylactic } \\
\text { ectoine }\end{array}$ & $0.0 \pm 0.0$ & $0.0 \pm 0.0$ & $0.5 \pm 0.8$ & $0.5 \pm 0.8$ \\
\hline & Active ectoine & $1.7 \pm 1.7$ & $1.4 \pm 0.7$ & $1.1 \pm 0.9$ & $0.3 \pm 0.6$ \\
\hline & $\begin{array}{l}\text { Calcium } \\
\text { phosphate }\end{array}$ & $1.9 \pm 0.5$ & $1.6 \pm 0.6$ & $1.1 \pm 0.4$ & $0.6 \pm 0.5$ \\
\hline \multirow[t]{3}{*}{ Coated tongue } & $\begin{array}{l}\text { Prophylactic } \\
\text { ectoine }\end{array}$ & $0.0 \pm 0.0$ & $0.2 \pm 0.6$ & $0.2 \pm 0.6$ & $0.0 \pm 0.0$ \\
\hline & Active ectoine & $1.4 \pm 0.9$ & $1.1 \pm 0.8$ & $0.4 \pm 0.9$ & $0.3 \pm 0.9$ \\
\hline & $\begin{array}{l}\text { Calcium } \\
\text { phosphate }\end{array}$ & $1.8 \pm 0.6$ & $1.6 \pm 0.6$ & $0.9 \pm 0.5$ & $0.4 \pm 0.5$ \\
\hline \multirow[t]{3}{*}{ Unpleasant breath } & $\begin{array}{l}\text { Prophylactic } \\
\text { ectoine }\end{array}$ & $0.2 \pm 0.4$ & $0.0 \pm 0.0$ & $0.3 \pm 0.9$ & $0.2 \pm 0.6$ \\
\hline & Active ectoine & $1.3 \pm 0.7$ & $0.9 \pm 0.8$ & $0.4 \pm 0.6$ & $0.1 \pm 0.4$ \\
\hline & $\begin{array}{l}\text { Calcium } \\
\text { phosphate }\end{array}$ & $1.7 \pm 0.6$ & $1.5 \pm 0.6$ & $0.9 \pm 0.8$ & $0.4 \pm 0.5$ \\
\hline \multirow[t]{3}{*}{$\begin{array}{c}\text { Decreased saliva } \\
\text { production }\end{array}$} & $\begin{array}{l}\text { Prophylactic } \\
\text { ectoine }\end{array}$ & $0.0 \pm 0.0$ & $0.2 \pm 0.6$ & $0.2 \pm 0.6$ & $0.3 \pm 0.7$ \\
\hline & Active ectoine & $1.2 \pm 0.7$ & $0.8 \pm 0.5$ & $0.4 \pm 0.9$ & $0.3 \pm 0.9$ \\
\hline & $\begin{array}{l}\text { Calcium } \\
\text { phosphate }\end{array}$ & $1.6 \pm 0.6$ & $1.5 \pm 0.6$ & $0.9 \pm 0.6$ & $0.3 \pm 0.5$ \\
\hline
\end{tabular}


Table 2 continued

\begin{tabular}{|c|c|c|c|c|c|}
\hline Symptom & Treatment & $\begin{array}{l}\text { V1 } \\
(\text { mean } \pm S D)\end{array}$ & $\begin{array}{l}\mathrm{V} 2 \\
(\text { mean } \pm \mathrm{SD})\end{array}$ & $\begin{array}{l}\text { V3 } \\
(\text { mean } \pm S D)\end{array}$ & $\begin{array}{l}\text { V4 } \\
(\text { mean } \pm S D)\end{array}$ \\
\hline \multirow[t]{3}{*}{ Pain } & $\begin{array}{l}\text { Prophylactic } \\
\text { ectoine }\end{array}$ & $0.0 \pm 0.0$ & $0.0 \pm 0.0$ & $0.6 \pm 0.7$ & $0.6 \pm 0.7$ \\
\hline & Active ectoine & $1.7 \pm 0.6$ & $1.2 \pm 0.7$ & $0.6 \pm 1.1$ & $0.3 \pm 0.6$ \\
\hline & $\begin{array}{l}\text { Calcium } \\
\text { phosphate }\end{array}$ & $1.6 \pm 0.8$ & $1.2 \pm 0.8$ & $0.9 \pm 0.8$ & $0.3 \pm 0.5$ \\
\hline \multirow[t]{3}{*}{ Swelling } & $\begin{array}{c}\text { Prophylactic } \\
\text { ectoine }\end{array}$ & $0.0 \pm 0.0$ & $0.0 \pm 0.0$ & $0.1 \pm 0.3$ & $0.0 \pm 0.0$ \\
\hline & Active ectoine & $0.4 \pm 0.8$ & $0.3 \pm 0.6$ & $0.2 \pm 0.6$ & $0.1 \pm 0.5$ \\
\hline & $\begin{array}{l}\text { Calcium } \\
\text { phosphate }\end{array}$ & $0.6 \pm 0.8$ & $0.5 \pm 0.6$ & $0.1 \pm 0.4$ & $0.1 \pm 0.3$ \\
\hline \multirow[t]{3}{*}{ Ulcer } & $\begin{array}{l}\text { Prophylactic } \\
\text { ectoine }\end{array}$ & $0.0 \pm 0.0$ & $0.0 \pm 0.0$ & $0.0 \pm 0.0$ & $0.0 \pm 0.0$ \\
\hline & Active ectoine & $0.6 \pm 0.8$ & $0.6 \pm 1.0$ & $0.2 \pm 0.6$ & $0.1 \pm 0.4$ \\
\hline & $\begin{array}{l}\text { Calcium } \\
\text { phosphate }\end{array}$ & $1.1 \pm 1.1$ & $0.7 \pm 0.8$ & $0.3 \pm 0.6$ & $0.1 \pm 0.3$ \\
\hline \multirow[t]{3}{*}{ Difficulties speaking } & $\begin{array}{c}\text { Prophylactic } \\
\text { ectoine }\end{array}$ & $0.0 \pm 0.0$ & $0.0 \pm 0.0$ & $0.0 \pm 0.0$ & $0.1 \pm 0.3$ \\
\hline & Active ectoine & $0.2 \pm 0.8$ & $0.2 \pm 0.6$ & $0.2 \pm 0.6$ & $0.1 \pm 0.5$ \\
\hline & $\begin{array}{l}\text { Calcium } \\
\text { phosphate }\end{array}$ & $0.2 \pm 0.8$ & $0.2 \pm 0.8$ & $0.0 \pm 0.0$ & $0.0 \pm 0.0$ \\
\hline \multirow[t]{3}{*}{$\begin{array}{l}\text { Difficulties } \\
\text { eating/drinking }\end{array}$} & $\begin{array}{l}\text { Prophylactic } \\
\text { ectoine }\end{array}$ & $0.0 \pm 0.0$ & $0.0 \pm 0.0$ & $0.6 \pm 0.8$ & $0.9 \pm 0.7$ \\
\hline & Active ectoine & $0.6 \pm 1.1$ & $0.6 \pm 1.1$ & $0.4 \pm 1.1$ & $0.3 \pm 0.7$ \\
\hline & $\begin{array}{l}\text { Calcium } \\
\text { phosphate }\end{array}$ & $0.3 \pm 0.8$ & $0.3 \pm 0.8$ & $0.1 \pm 0.3$ & $0.1 \pm 0.3$ \\
\hline
\end{tabular}

\section{Active Treatment with Ectoine vs. Calcium Phosphate}

The distribution of mucositis grades in the active ectoine group at inclusion was 8 patients (40\%) with grade I, 9 patients (45\%) with grade II, and 3 patients $(15 \%)$ with grade III. After 21 days of treatment, 16 patients $(80 \%)$ were completely cured, 2 patients (10\%) had grade I, 1 patient (5\%) had grade II, and 1 patient had grade III. At
$\mathrm{V} 1$, the calcium phosphate group consisted of 3 patients (20\%) with grade I, 11 patients $(73.3 \%)$ with grade II, and 1 patient (6.7\%) with grade IV. At V4, 6 patients (42.9\%) were completely cured, 7 patients $(50.0 \%)$ had grade I, and 1 patient (7.1\%) had grade II (Table 1).

Analyses of the symptom scores show that patients in the two groups had comparable symptoms at V1. Symptoms such as dry mucosa, mucosa irritation, coated tongue, 

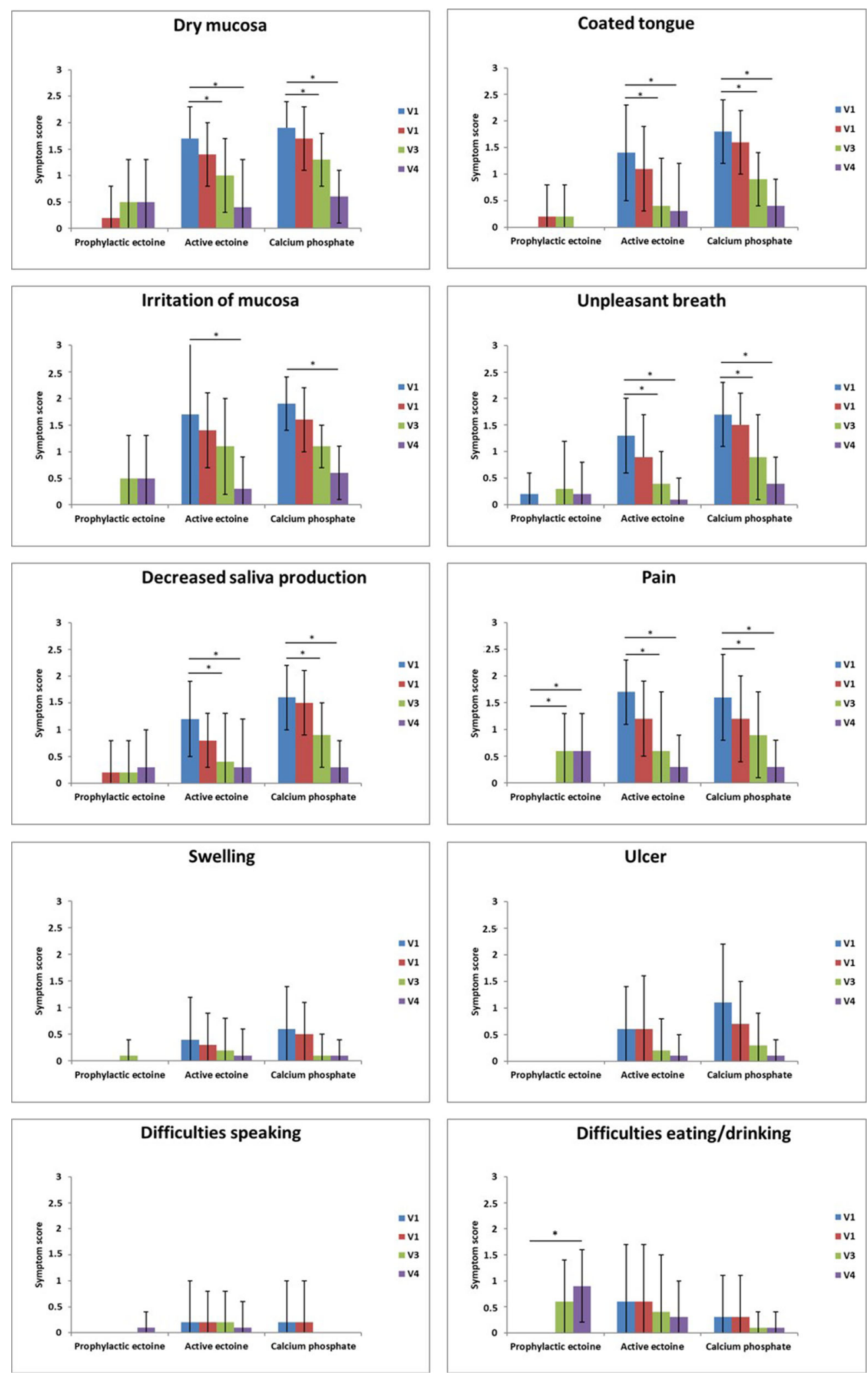
4Fig. 1 Symptom scores assessed by the physicians together with the patients at V1, V2, V3, and V4 ( $0=$ none, $1=$ mild, 2 = moderate, and $3=$ severe). Values plotted are mean \pm standard deviation (SD). Significant differences between visits were determined using the Wilcoxon signed-rank test. ${ }^{*}$ Indicates $P<0.05$

unpleasant breath, decreased saliva production, and pain were mild or moderate at V1 and reduced to very mild or mild at V4. Significant reductions in all symptoms, except for irritated mucosa, were recorded at V3 in both groups $(P<0.05)$. Symptoms such as swelling, ulcer, difficulties speaking, and difficulties eating/drinking were very mild or mild at V1 and mostly resolved at V4 (Table 2, Fig. 1). The reductions in symptom scores were not significantly different between groups.

\section{Patients' Assessments}

The overall effectiveness and tolerability of the treatment as well as its effectiveness against individual symptoms were assessed as "good" and "very good" by patients in both ectoine groups and as "good" by calcium phosphate patients. The superiority of the active ectoine group over the calcium phosphate group was significant $(P<0.05)$. The difference between the two ectoine groups was not significant (Fig. 2).

In the prophylactic ectoine arm, $90 \%$ of patients would buy the product (mean score $=$ $1.9 \pm 0.3$ ), and $100 \%$ would recommend the product $(2.0 \pm 0.0)$. In the active ectoine group, $80 \%$ of patients would buy the product $(1.8 \pm 0.6)$, and $87.6 \%$ would recommend the product $(1.8 \pm 0.6)$. It should be understood that the term "this product" referred to the product and the specific treatment regimen (i.e., prophylactic or active treatment with ectoine), not only the product itself. In contrast, $40 \%$ of calcium phosphate patients would buy the product $(1.3 \pm 0.6)$, and $53.3 \%$ would recommend the product $(1.5 \pm 0.5)$. The difference between the active ectoine group and the calcium phosphate group was significant $(P<0.05)$ (Fig. 3$)$.

\section{Safety}

One patient suffered from exsiccosis and fever 2 months after the completion of the study and died shortly after that. These events were classified as unrelated to the study treatment.

\section{DISCUSSION}

Patients applying ectoine prophylactically show few mild or moderate symptoms throughout the study. As a result of the lack of placebo, it is not possible to extrapolate the actual percentage of patients who would not develop mucositis at all, even without being treated prophylactically. In the literature, the incidence of mucositis following chemotherapy with sunitinib ranges from $12 \%$ to $29 \%$ [25-27]. In general, $20-40 \%$ of patients receiving conventional chemotherapy develop mucositis [4]. Considering that the majority of patients did not necessarily need to be treated, prophylactic treatment with ectoine may nevertheless be beneficial for patients in whom symptoms of dry mucosa, coated tongue, unpleasant breath, and decreased saliva production occur. However, one should not disregard the study design and patients' medical history when making cross-study comparisons. Therefore, we cannot draw robust conclusions about the prophylactic effects of ectoine on the basis of the results of this study.

Ectoine mouthwash seemed to be better than calcium phosphate mouthwash for the active treatment of oral mucositis. The reductions in symptom scores were comparable; however, patients rated the effectiveness and tolerability of ectoine more favorably. We found conflicting evidence for the effectiveness and tolerability of calcium phosphate mouthwash in the literature. In a systemic review of 30 studies in patients undergoing chemotherapy and/or radiotherapy, 24 studies reported that calcium phosphate mouthwash reduced symptoms and analgesics needed as well as the incidence and mean days of the disease [28]. However, in many studies the results were not statistically significant. Recent data suggests that calcium phosphate mouthwash is not more beneficial 

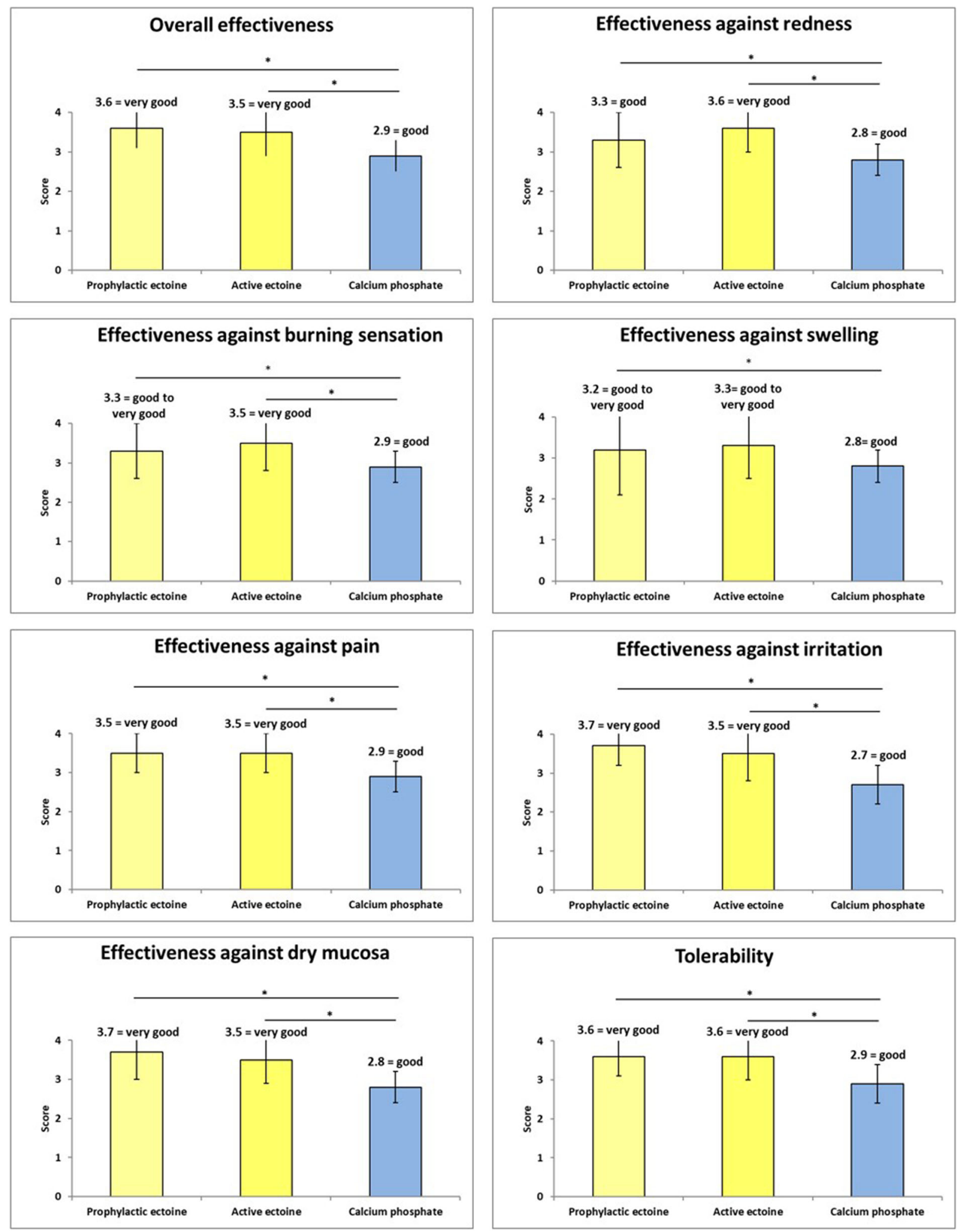
4Fig. 2 Effectiveness and tolerability of investigational products assessed by the patients at $\mathrm{V} 4$ ( $0=$ very poor, 1 = poor, 2 = neither poor nor good, 3 = good, and $4=$ very good). Data plotted are mean \pm SD. Differences between groups were analyzed using the two-sided Fisher's exact test. ${ }^{*}$ Indicates $P<0.05$

than saline/aspirin mouthwash, cryotherapy, or even placebo [29-31]. Another study showed that calcium phosphate mouthwash did not reduce the incidence of WHO mucositis grade II below historic rates [32]. Taken together, while the evidence-based efficacy of calcium phosphate mouthwash is still disputable, ectoine mouthwash can be a viable treatment option for oral mucositis.

Recently, two studies have shown that ectoine reduced DNA damage caused by ionizing radiation. The authors described ectoine as a hydroxyl radical scavenger and suggested its use as a protective agent in radiotherapy [33, 34]. Hence, one might extrapolate that ectoine mouthwash can be beneficial not only for chemotherapy-related but also for radiotherapyand radiochemotherapy-related oral mucositis.

This study was conducted as a non-interventional study under routine clinical practice. Though placebo control and randomization were not permitted in this study design according to $\$ 17$ para (1), point c) of Government Regulation 235/2009 (X.20.) effective in Hungary, this study compared ectoine

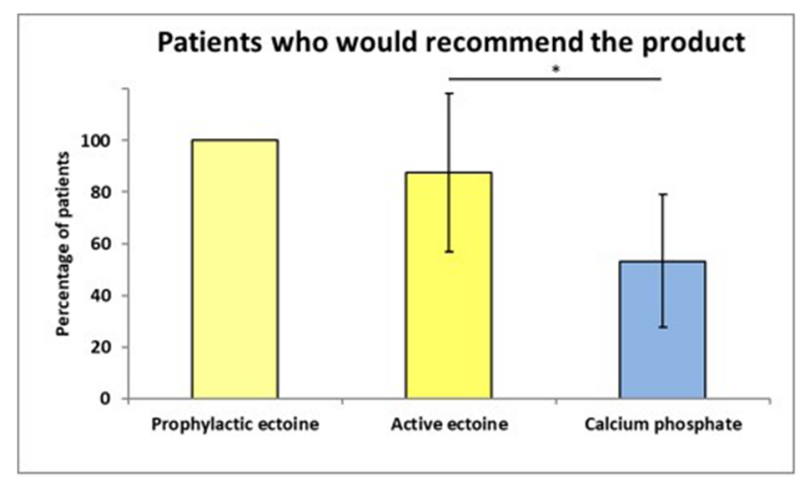

Fig. 3 Patients' likelihood of buying or recommending the product after the study, which confirms their satisfaction with the treatment results. Significant differences between mouthwash to an active control-calcium phosphate mouthwash. This study design allows for comparison of the effectiveness between these two treatments under real-life conditions. The relatively low number of patients was a limitation in our study. However, the similar baseline characteristics allowed us to compare the effectiveness of the treatment between groups.

Given that ectoine is a natural substance that has remarkably few side effects, we recommend ectoine mouthwash for the active treatment of oral mucositis. Follow-up, placebo-controlled studies are needed to confirm its prophylactic effects.

\section{CONCLUSIONS}

Mucositis following chemotherapy can be safely and effectively treated with ectoine-containing mouthwash. Significant reductions of symptoms were detected on day 14 . After 21 days of treatment, symptoms were almost completely resolved. Physicians' assessments deduce that ectoine is as effective as calcium phosphate. According to patients' assessments, ectoine is more effective and tolerable than calcium phosphate. Further studies are needed to confirm the effects of ectoine for the prophylaxis of mucositis.

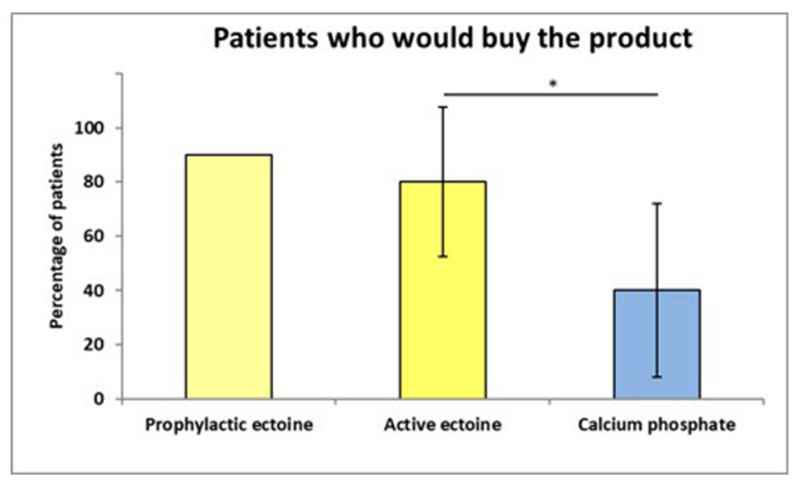

treatment groups were determined using the two-sided Fisher's exact test. ${ }^{*}$ Indicates $P<0.05$ 


\section{ACKNOWLEDGEMENTS}

The authors would like to thank Gena Kittel for proofreading the manuscript. The authors thank the participants of the study.

Funding. Sponsorship for this study and article processing charges were funded by bitop AG (Dortmund, Germany). All authors had full access to all of the data in this study and take complete responsibility for the integrity of the data and accuracy of the data analysis.

Authorship. All named authors meet the International Committee of Medical Journal Editors (ICMJE) criteria for authorship for this article, take responsibility for the integrity of the work as a whole, and have given their approval for this version to be published.

Disclosures. Van-Anh Dao has nothing to disclose. Andreas Bilstein is an employee of bitop AG (Dortmund, Germany). Sabrina Overhagen is an employee of bitop AG (Dortmund, Germany). Lajos Géczi has received support from bitop AG (Dortmund, Germany). Zoltán Baráth has received support from bitop AG (Dortmund, Germany). Ralph Mösges reports personal fees from ALK, grants from ASIT biotech, personal fees from allergopharma, personal fees from Allergy Therapeutics, grants and personal fees from Bencard, grants from Leti, grants, personal fees, and non-financial support from Lofarma, non-financial support from Roxall, grants and personal fees from Stallergenes, grants from Optima, personal fees from Friulchem, personal fees from Hexal, personal fees from Servier, personal fees from Klosterfrau, non-financial support from Atmos, personal fees from Bayer, non-financial support from Bionorica, personal fees from FAES, personal fees from GSK, personal fees from MSD, personal fees from Johnson \& Johnson, personal fees from Meda, personal fees and non-financial support from Novartis, non-financial support from Otonomy, personal fees from Stada, personal fees from UCB, non-financial support from Ferrero, grants from bitop AG, grants from
Hulka, personal fees from Nuvo, grants from Ursapharm, outside the submitted work.

Compliance with Ethics Guidelines. All procedures performed in studies involving human participants were in accordance with the ethical standards of the institutional and/or national research committee and with the 1964 Declaration of Helsinki and its later amendments or comparable ethical standards. Informed consent was obtained from all individual participants included in the study.

Data Availability. All data generated or analyzed during this study are included in this published article/as supplementary information files.

Open Access. This article is distributed under the terms of the Creative Commons Attribution-NonCommercial 4.0 International License (http://creativecommons.org/licenses/ by-nc/4.0/), which permits any noncommercial use, distribution, and reproduction in any medium, provided you give appropriate credit to the original author(s) and the source, provide a link to the Creative Commons license, and indicate if changes were made.

\section{REFERENCES}

1. Jones JA, Avritscher EB, Cooksley CD, Michelet M, Bekele BN, Elting LS. Epidemiology of treatmentassociated mucosal injury after treatment with newer regimens for lymphoma, breast, lung, or colorectal cancer. Supp Care Cancer. 2006;14(6):505-15.

2. Wardley AM, Jayson GC, Swindell R, et al. Prospective evaluation of oral mucositis in patients receiving myeloablative conditioning regimens and haemopoietic progenitor rescue. $\mathrm{Br} \mathrm{J}$ Haematol. 2000;110(2):292-9.

3. Naidu MU, Ramana GV, Rani PU, Mohan IK, Suman A, Roy P. Chemotherapy-induced and/or radiation therapy-induced oral mucositis-complicating the treatment of cancer. Neoplasia. 2004;6(5):423-31. 
4. Lalla RV, Bowen J, Barasch A, et al. MASCC/ISOO clinical practice guidelines for the management of mucositis secondary to cancer therapy. Cancer. 2014;120(10):1453-61.

5. Thomson M, Quinn B, Horn J, et al. Mouth care guidance and support in cancer and palliative care (second edition). The United Kingdom Oral Mucositis in Cancer Care Group (UKOMiC). 2015.

6. McGuire DB, Fulton JS, Park J, et al. Systematic review of basic oral care for the management of oral mucositis in cancer patients. Support Care Cancer. 2013;21(11):3165-77.

7. Sonis ST. Oral mucositis in head and neck cancer: risk, biology, and management. Am Soc Clin Oncol Educ Book. 2013. https://doi.org/10.1200/EdBook_ AM.2013.33.e236

8. Sonis ST. The pathobiology of mucositis. Nat Rev Cancer. 2004;4(4):277-84.

9. Sonis ST. Oral mucositis in cancer therapy. J Supp Oncol. 2004;2(6 Suppl 3):3-8.

10. Sonis ST, Elting LS, Keefe D, et al. Perspectives on cancer therapy-induced mucosal injury: pathogenesis, measurement, epidemiology, and consequences for patients. Cancer. 2004;100(9 Suppl):1995-2025.

11. Sydlik U, Gallitz I, Albrecht C, Abel J, Krutmann J, Unfried K. The compatible solute ectoine protects against nanoparticle-induced neutrophilic lung inflammation. Am J Respir Crit Care Med. 2009;180(1):29-35.

12. Unfried $\mathrm{K}$, Kroker $\mathrm{M}$, Autengruber A, Gotic $\mathrm{M}$, Sydlik U. The compatible solute ectoine reduces the exacerbating effect of environmental model particles on the immune response of the airways. J Allergy (Cairo). 2014;2014:708458.

13. Unfried K, Kramer U, Sydlik U, et al. Reduction of neutrophilic lung inflammation by inhalation of the compatible solute ectoine: a randomized trial with elderly individuals. Int J Chron Obstruct Pulmon Dis. 2016;11:2573-83.

14. Peuschel H, Sydlik U, Grether-Beck S, et al. Carbon nanoparticles induce ceramide- and lipid raft-dependent signalling in lung epithelial cells: a target for a preventive strategy against environmentally-induced lung inflammation. Part Fibre Toxicol. 2012;9:48.

15. Peuschel H, Sydlik U, Haendeler J, et al. c-Src-mediated activation of Erk1/2 is a reaction of epithelial cells to carbon nanoparticle treatment and may be a target for a molecular preventive strategy. Biol Chem. 2010;391(11):1327-32.
16. Sydlik U, Peuschel H, Paunel-Gorgulu A, et al. Recovery of neutrophil apoptosis by ectoine: a new strategy against lung inflammation. Eur Respir J. 2013;41(2):433-42.

17. Grether-Beck S, Timmer A, Felsner I, Brenden $\mathrm{H}$, Brammertz D, Krutmann J. Ultraviolet A-induced signaling involves a ceramide-mediated autocrine loop leading to ceramide de novo synthesis. J Invest Dermatol. 2005;125(3):545-53.

18. Dwivedi M, Brinkkotter M, Harishchandra RK, Galla HJ. Biophysical investigations of the structure and function of the tear fluid lipid layers and the effect of ectoine. Part B: artificial lipid films. Biochim Biophys Acta. 2014;1838(10):2716-27.

19. Harishchandra RK, Wulff S, Lentzen G, Neuhaus T, Galla HJ. The effect of compatible solute ectoines on the structural organization of lipid monolayer and bilayer membranes. Biophys Chem. 2010;150(1-3):37-46.

20. Abdel-Aziz H, Wadie W, Abdallah DM, Lentzen G, Khayyal MT. Novel effects of ectoine, a bacteriaderived natural tetrahydropyrimidine, in experimental colitis. Phytomedicine. 2013;20(7):585-91.

21. Müller D, Lindemann T, Shah-Hosseini K, et al. Efficacy and tolerability of an ectoine mouth and throat spray compared with those of saline lozenges in the treatment of acute pharyngitis and/or laryngitis: a prospective, controlled, observational clinical trial. Eur Arch Otorhinolaryngol. 2016;273:2591-7.

22. Sonnemann U, Moller M, Bilstein A. Noninterventional open-label trial investigating the efficacy and safety of ectoine containing nasal spray in comparison with beclomethasone nasal spray in patients with allergic rhinitis. J Allergy (Cairo). 2014;2014:297203.

23. Werkhäuser N, Bilstein A, Sonnemann U. Treatment of allergic rhinitis with ectoine containing nasal spray and eye drops in comparison with azelastine containing nasal spray and eye drops or with cromoglycic acid containing nasal spray. J Allergy (Cairo). 2014;2014:176597.

24. WHO. WHO handbook for reporting results of cancer treatment. Geneva: WHO; 1979.

25. Motzer RJ, Rini BI, Bukowski RM, et al. Sunitinib in patients with metastatic renal cell carcinoma. JAMA. 2006;295(21):2516-24.

26. Powles T, Sarwar N, Jones R, et al. An indirect comparison of the toxicity of sunitinib and pazopanib in metastatic clear cell renal cancer. Eur J Cancer. 2012;48(17):3171-6. 
27. Srinivas S, Stein D, Teltsch DY, Tao S, Cisar L, Ramaswamy K. Real-world chart review study of adverse events management in patients taking tyrosine kinase inhibitors to treat metastatic renal cell carcinoma. J Oncol Pharm Pract. 2017. https://doi. org/10.1177/1078155217719583.

28. Quinn B. Efficacy of a supersaturated calcium phosphate oral rinse for the prevention and treatment of oral mucositis in patients receiving highdose cancer therapy: a review of current data. Eur J Cancer Care (Engl). 2013;22(5):564-79.

29. Svanberg A, Ohrn K, Birgegard G. Caphosol(®) mouthwash gives no additional protection against oral mucositis compared to cryotherapy alone in stem cell transplantation. A pilot study. Eur J Oncol Nurs. 2015;19(1):50-3.

30. Wong KH, Kuciejewska A, Sharabiani MT, et al. A randomised controlled trial of Caphosol mouthwash in management of radiation-induced mucositis in head and neck cancer. Radiother Oncol. 2017;122(2):207-11.

31. Treister N, Nieder M, Baggott C, et al. Caphosol for prevention of oral mucositis in pediatric myeloablative haematopoietic cell transplantation. $\mathrm{Br} \mathrm{J}$ Cancer. 2017;116(1):21-7.

32. Rao NG, Trotti A, Kim J, et al. Phase II multicenter trial of Caphosol for the reduction of mucositis in patients receiving radiation therapy for head and neck cancer. Oral Oncol. 2014;50(8):765-9.

33. Hahn MB, Meyer S, Schroter MA, Kunte HJ, Solomun T, Sturm H. DNA protection by ectoine from ionizing radiation: molecular mechanisms. Phys Chem Chem Phys. 2017;19(37):25717-22.

34. Schroter MA, Meyer S, Hahn MB, Solomun T, Sturm $\mathrm{H}$, Kunte HJ. Ectoine protects DNA from damage by ionizing radiation. Sci Rep. 2017;7(1):15272. 